\title{
Assessment of corrosion-induced bond deterioration in reinforced concrete: towards a splitting crack-based approach
}

Citation:

Mak, M.W.T. and Lees, J.M. (2021). Assessment of corrosion-induced bond deterioration in reinforced concrete: towards a splitting crack-based approach. Proceedings of the IABSE Congress - Resilient Technologies for Sustainable Infrastructure. 3-5 February 2021, Christchurch, New Zealand.

Version:

Accepted for publication 


\title{
Assessment of corrosion-induced bond deterioration in reinforced concrete: towards a splitting crack-based approach
}

\author{
Michele Win Tai Mak, Janet M. Lees \\ University of Cambridge, Cambridge, UK
}

Contact: $\underline{\text { mwtm2@cam.ac.uk }}$

\begin{abstract}
Reinforced concrete structures are subjected to several sources of deterioration that can reduce their load-resisting capacity over time. This has significant consequences for the management of infrastructure, leading to high costs of maintenance, repair, strengthening and premature decommissioning. Assessing the residual capacity of structures is challenging but paramount to manage the infrastructure network effectively. Corrosion of the internal steel reinforcement is among the main causes of deterioration in reinforced concrete bridges. The subsequent reduction in steel-to-concrete bond strength is difficult to evaluate with accuracy. There is no unified theory of general validity. Most existing models adopt measures of the level of corrosion as the key parameter to evaluate the bond reduction. In this paper, a different approach is investigated. Corrosion-induced splitting crack widths are used as the fundamental indicator of bond strength reduction, irrespective of the associated degree of steel corrosion. Available experimental results on deformed steel bars embedded in concrete subjected to either natural or accelerated corrosion, with or without transverse reinforcement, are analysed and compared with a different perspective. The analysis indicates that this new splitting crack-based approach can lead to more accurate predictions. This contributes to a better understanding of the fundamental principles underlying bond of corroded reinforcing bars. Enhanced assessment strategies can lead to a reduction of the safety risks, maintenance costs and environmental footprint of the infrastructure network.
\end{abstract}

Keywords: Anchorage; bridge; corrosion; degradation; drone; durability; inspection.

\section{Introduction}

Reinforced concrete structures age over time. They are subjected to sources of deterioration, such as repeated loading and direct exposure to environmental conditions, that can result in a reduction in load-carrying capacity. Corrosion of the internal steel reinforcement is often considered the most severe cause of deterioration in reinforced concrete bridges. This can be due to exposure to natural aggressive environments, or the use of de-icing salts on roads that can leak through protective layers, permeate and diffuse within the concrete. The evolving condition of the infrastructure network is monitored and inspected regularly to ensure its safety and functionality. Asset management currently relies heavily on visual inspections. For this reason, indicators of structural deterioration that are visible on the outer concrete surface are crucial.

\section{Background}

Reinforcement corrosion has different consequences. The oxidation of the steel leads to a 
reduction in cross sectional area of a bar which is proportionally related to the axial force the bar can withstand. Corrosion products also weaken the steel-to-concrete interface, reducing the ability to transfer forces between the two materials through friction. Moreover, corrosion products have a lower density than the parent metal. If their development is confined, it leads to expansions that induce a stress field in the concrete surrounding the steel bars. Compressive stresses develop radially, whereas tensile hoop stresses develop in the tangential direction. When the hoop stresses exceed the concrete tensile capacity, the concrete cracks. As expansive pressure increases, the cracks can reach the outer concrete surface. These splitting cracks in the concrete surrounding the reinforcement affect the load transfer capacity between the two materials. The reduction in steelto-concrete bond due to corrosion can be critical even for low levels of corrosion, before the loss of cross-sectional area is of concern. This compromises the structural behaviour of reinforced concrete, which relies on the combined action between the two materials. In particular, the load-bearing capacity can be reduced significantly if bond deterioration occurs in the anchorage zones of straight bars. Some structural elements are more critical to bond deterioration than others due to a combination of factors such as the distribution of internal forces, reinforcement layout, application of external loads and exposure to chemical attack. Reinforced concrete half-joints, where the depth of a structural element is reduced at the supports, are an example of a structural configuration where the deterioration of the anchorage of longitudinal tension bars can be critical, as indicatively shown in Figure 1.

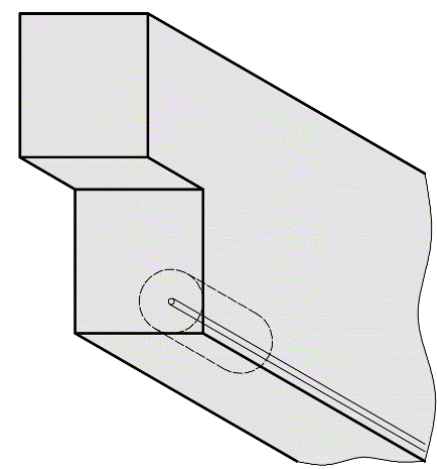

Figure 1. Anchorage zone of bottom reinforcement bars in the full depth of a half-joint.

\subsection{Conventional approaches}

Corrosion of the internal steel reinforcement in concrete and its structural consequences have been studied extensively in the past. In broad terms, the majority of the existing literature can be divided into two types of studies: those correlating corrosion to cracking and those linking corrosion to bond deterioration.

The first type of study investigates the correlation between surface cracking measurable on the outer concrete surface and the level of corrosion of the internal steel bars in an attempt to develop models than could be used as non-destructive assessment tools for visual inspections. Comparisons of results from such studies showed scatter [1-3]. Bossio et al. [2] partially attributed the variability to the influence of the relative position and distance between cracks and the nature of corrosion products, whose volumetric expansion coefficients can vary significantly [1]. Zhao et al. [4] observed that corrosion products distribute in the corrosionaccommodating region around the bar, and diffuse differently in the internal restrained cracks and in those that reached the outer concrete surface. The amount of corrosion products that can flow within the concrete structure is therefore another parameter that may partially contribute to the variability in the experimental results.

The second type of study investigates bond degradation as a function of the level of corrosion. A comprehensive overview of the problem and the relevant scientific work on this subject can be found within the fib Bulletin 10 [5]. More recent literature reviews can be found elsewhere [6-7]. In broad terms, there seems to be a general consensus across studies on the overall trends. The proposed models typically agree well with the experimental results they have been calibrated on. However, despite the similarity in trends, there is little agreement between proposed models and a lack of general validity [1-3,6, 8-10]. Despite the common trend of an initial increase in bond strength for low levels of corrosion and a subsequent decrease in bond for more severe corrosion, the results are characterised by dispersion and variability. The scatter can be attributed to the variability in the material properties, their spatial distribution and the 
different confinement conditions. Both steel and concrete are heterogeneous materials and exhibit a degree of variability in their properties, despite the attempt to control them during the fabrication process. The variability in the properties of corroded reinforced concrete structures is even greater, due to the complex nature of the corrosion process, the chemistry involved and the differences between natural and laboratory exposure conditions.

From an assessment implementation perspective, two separate models would have to be used: a first one to correlate the measured surface cracks with the 'hidden' internal corrosion, and then a separate model using this information on the level of corrosion to estimate the bond strength of the embedded reinforcement. It follows that the uncertainty associated with each model is cumulative and contributes to greater uncertainty overall. This lack of accuracy justifies the need for a new approach.

\section{A splitting crack-based approach}

The significant impact of longitudinal cracking on the bond behaviour of reinforcing bars has been identified by several authors. The steel bars embedded in the specimens are corroded with different techniques: with an impressed current, exposure in environmental chambers, or directly in natural environments. The specimens are then subjected to bond tests. There is no universally accepted test set-up to measure bond, and each configuration has both advantages and disadvantages. The fundamental difference between them lies in the stresses in the concrete. The relative position of the steel bar with respect to the point of application of the external force and support reactions induces a different stress field in the concrete surrounding the bar. This in turn has an impact on the bond behaviour of the embedded bar. Figure 2 summarises some of the common experimental bond test configurations that have been adopted in the work analysed in this publication. These include: a) concentric pull-out tests; b-c) cantilever, also known as eccentric or beam-end tests; $d$ ) indirectly supported four-point bending tests.

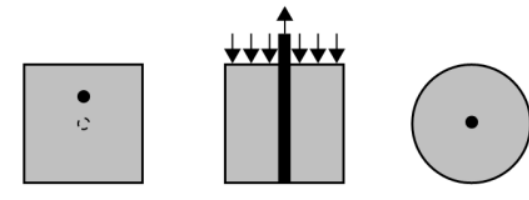

a)

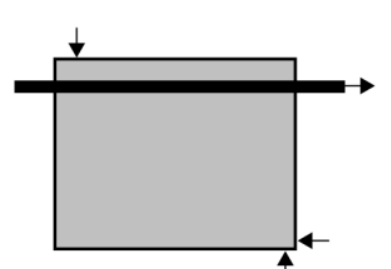

b)

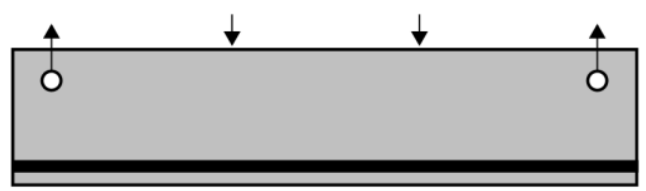

d)

Figure 2. Common types of bond test configurations in the literature.

In accelerated corrosion and pull-out bond tests, Al-Sulaimani et al [11] identified four stages (noncorroded, pre-cracking, cracking and postcracking), characterised by a different load-slip behaviour and a clear difference before and after the onset of cracking. No reduction in bond strength was observed for corroded bars before surface cracks appeared. The authors reported a trend of increasing slip that corresponded to the peak load, but only in the post-cracking phase. Based on accelerated corrosion and cantilever bond tests, similar conclusions were drawn by Almusallam et al. [12] who acknowledged that cracking plays a critical role in the bond behaviour. However, they observed that a high bond strength immediately after cracking is possible. A decrease in slip at peak load in the pre-cracking stage, and an increase in slip in the post-cracking stage were also reported. As the failure mode changed from pullout (uncorroded specimens) to concrete splitting (corroded specimens), a sudden drop in the loadslip curves was noted. For high levels of corrosion, the ultimate bond strength did not vary with increasing mass loss, asymptotically reaching a limit. The same phenomenon was observed by Cabrera and Ghodoussi [13] who suggested that significant degradation of the lugs would lead to a friction-type behaviour similar to that of plain bars. 
Fang et al. [14] carried out accelerated corrosion and concentric bond tests on smooth and deformed bars with and without stirrups. For the deformed bars, they observed a substantial reduction in bond strength for unconfined specimens, similarly to other studies. However, they reported no substantial influence of corrosion in the presence of stirrups. Although they reported that all specimens exhibited corrosion-induced cracking and failed by splitting, it should be noted that they did not investigate the evolution or influence of crack widths in the experiments. Their trends refer to the evolution of bond strength as a function of the percentage mass loss. They also reported that the slip at peak load tended to decrease as the level of corrosion increased, similar to results by others [11]. For smooth bars, they observed different trends: for greater levels of mass loss, unconfined bars showed an increase followed by a decrease in bond strength. Confined smooth bars instead showed an increase in bond strength and no decrease up to mass losses over $5 \%$. Coccia et al. [10] performed accelerated corrosion and concentric pull-out tests on unconfined cubic specimens. They also observed no reduction in bond strength before cracking for low levels of corrosion, which suggests that surface splitting cracks may be directly related to bond deterioration. In order to calibrate and validate their numerical analyses, Fischer et al. [9, 15] carried-out pull-out tests on beam-end specimens, with and without stirrups. They observed a reduction in bond strength with increasing crack width, and this was particularly significant in the absence of transverse reinforcement. They identified crack width as a potentially good indicator of bond deterioration, acknowledging that more investigations would be necessary to identify the influence of parameters such as concrete cover and bar diameter. An exponential relationship between bond strength and average crack width in specimens without stirrups was proposed. Law et al. [16] also investigated the correlation between surface crack widths and bond strength, testing beam-end specimens. They observed that bond strength had a stronger correlation with surface crack widths than the level of corrosion. Crack widths were measured in the direction normal to the longitudinal reinforcement, irrespective of the actual crack orientation. They reported that maximum crack width values indicated a better correlation than average values. They tested specimens with and without stirrups and noted a difference in bond strength degradation as surface crack widths increased: in unconfined specimens, all specimens that exhibited corrosion induced cracking had bond strength values lower than the uncorroded reference case. In confined specimens, small crack widths corresponded to an increase in bond strength, followed by a decrease. The same authors separately reported a dependence of the bond behaviour on the cover-to-diameter ratio [8]. Linear or logarithmic relationships gave the best fit with their experimental results. They attributed the better correlation to the fact that beyond certain crack width values, increasing corrosion has a smaller impact on crack progression. Mak et al. [3] carried out accelerated corrosion testing and concentric pull-out tests on cylindrical specimens. By changing the sealing conditions of the specimens, they varied the amount of corrosion products flowing out without developing expansive pressure. Similar levels of corrosion therefore led to different crack width and bond deterioration. They reported that the total surface crack widths were more accurate indicators of bond deterioration than conventional measures of corrosion such as mass loss or attack penetration. They concluded that crack width can be interpreted as a measure of the net amount of corrosion inducing expansion and loss of interlock between steel ribs and concrete. Lin et al. [17] performed accelerated corrosion and eccentric pull-out tests, investigating the correlation between surface crack widths and bond deterioration. They studied the influence of several parameters such as bond length, concrete cover, corrosion level, confining reinforcement. They identified three stages, namely cracking initiation, propagation and further propagation, where the influence of different parameters was different in each stage. Initially, the concrete adjacent to the steel bar resisted the opening of the cracks due to its fracture energy where a larger $\mathrm{c} / \mathrm{d}$ led to reduced surface crack growth. At a later stage, when cracks had fully developed, the strains in the concrete cover had been released and the concrete blocks tended to have a rigid body-type of behaviour. In this stage, large concrete covers lead to greater surface cracks 
due to a 'geometrical magnification' effect: for a given rigid-body rotation, greater cover distances lead to greater crack widths on the surface. Banba et al. [18] investigated the influence of confinement stresses on bond degradation. Confinement stresses were defined as the average nominal radial stress at the steel-to-concrete interface. Their experimental programme was divided into two types of tests. In the first type of test, cubic concrete specimens with an eccentric steel bar were subjected to accelerated corrosion using an impressed current. Bond pull-out tests were subsequently performed on the same specimens. Steel stresses were measured with strain gauges, and crack widths were measured on the concrete surface throughout the tests. In the second type of test, steel pipes were cast into prismatic concrete specimens. Expansive pressure was generated artificially with a 'non-explosive demolition agent', and confinement stresses were measured with strain gauges installed on the outer surface of the steel pipe. External crack widths were also measured with transducers. They developed a model that would correlate the results of the two type of tests, effectively linking corrosion-induced bond deterioration from the first set of tests to the confinement stresses of the second set of tests via the surface crack widths. They observed a correlation between crack width and bond strength. However, they also noted that for a given crack width, greater cover distances were associated with greater residual bond strength. In other words, bond deterioration as a function of surface crack widths was more severe for small cover distances. Since a biunivocal relationship was not found with any parameter, they postulated that bond deterioration may be directly correlated to confinement stresses. Such confinement stresses appeared to increase with greater covers and greater concrete strength. Where the cover distance was different in two directions, they concluded that confinement stresses did not depend on the greater cover distance, but only on the smaller one, where surface cracks would first develop. These conclusions are consistent with Tepfer's Thick Walled Cylinder formulation [19]. Banba et al. [18] found that confinement stresses decreased exponentially with increasing crack widths, approaching zero values for crack widths of approximately $1.0 \mathrm{~mm}$. They also reported that the rate at which confinement stresses declined due to crack width opening appeared to be independent of cover thicknesses or concrete compressive strength. On the other hand, bond strength degradation depended on the concrete quality, and decreased exponentially with corrosioninduced crack widths. They concluded that there was a linear relationship between confinement stresses and bond strength, and this linearity was not affected by cover thickness or reinforcement diameter. They proposed analytical bond stressslip models in agreement with their experimental results. They observed that where bleeding led to voids around the reinforcement bars, the empty volume between steel and concrete would be filled with corrosion products, hence bond degradation would not occur. Presumably this is because expansive pressure and concrete cracking would not be generated. Apostolopoulos et al. [20] investigated the relationship between surface cracks and bond reduction. The specimens were corroded using an impressed current and subsequently subjected to eccentric bond tests. They observed that corrosion-induced cracking was associated with an exponential reduction in bond strength. For the same bar size of $16 \mathrm{~mm}$, they tested two cover thicknesses of 25 and $40 \mathrm{~mm}$. Interestingly, greater concrete cover led to a more rapid decrease in bond strength in some cases with transverse reinforcement. Plain concrete exhibited the most severe bond degradation for a given crack width. Increasing amounts of transverse reinforcement led to greater bond strength values. However, a few test results exhibited an opposing trend. Specimens with the lowest concrete cover of $25 \mathrm{~mm}$ and the greatest amount of transverse reinforcement (i.e. $8 \mathrm{~mm}$ stirrups spaced $60 \mathrm{~mm}$ ) indicated an increase in bond strength for small crack widths, before deterioration started. Tahershamsi et al. [21] investigated the correlation between crack widths and anchorage capacity of naturally corroded bridge girders that had been in service for 32 years. For given levels of corrosion, they observed larger crack widths and lower bond strengths than previous authors that had used an impressed current. However, the reduction in bond strength was less significant than the results available in the literature if related to crack widths. They partially attributed this discrepancy to the 
difference between natural corrosion and accelerated testing, but also to the freeze-thaw that the bridge was naturally subjected to, and the larger spacing of transverse reinforcement.

Although the limited amount of data does not facilitate clear conclusions, it could be postulated that when the contribution of confinement due to transverse reinforcement is significant (compared to that due to concrete cover), small cracks enable the confining steel to be 'activated' resulting in an uplift of bond strength. Presumably, as corrosioninduced crack widths increase, such beneficial effect is outweighed by the loss of mechanical interlock due to crack opening. Yang et al. [22] carried out an experimental programme in different stages. Their objective was to isolate the impact of different corrosion-induced phenomena on bond degradation. Their experimental programme was divided into 4 specimen groups. The first group consisted of uncorroded reference specimens. In the second group, specimens were subjected to accelerated corrosion and pull-out tests. In the third group, after the accelerated corrosion phase, the bars were cleaned and re-cast into specimens with the same geometry and new concrete. The new specimens with damaged cleaned bars were then subjected to pull-out tests. In the fourth group, after the accelerated corrosion phase, the bars were removed from the specimens but not cleaned and the corrosion products were left on the steel surface. These bars were then re-

\section{Unconfined Specimens}

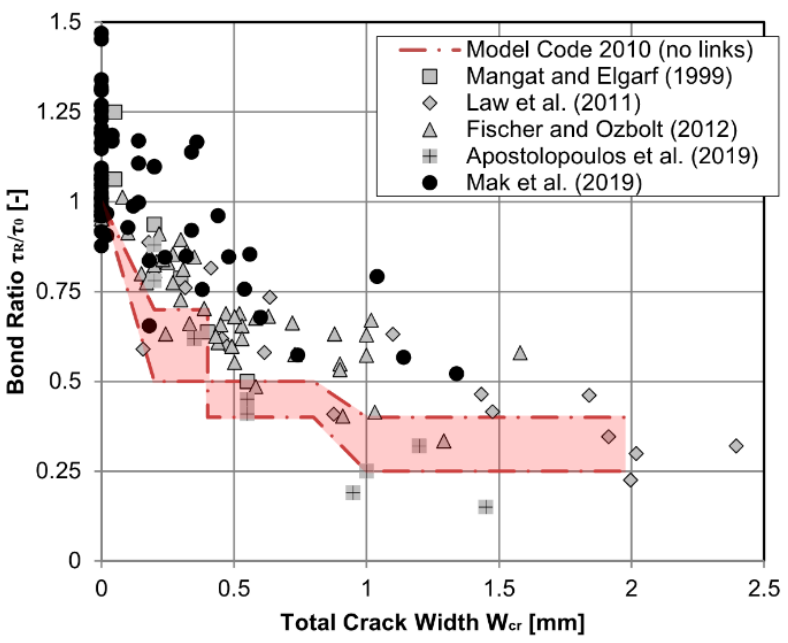

a) cast into new specimens and subsequently tested in pull-out. The crack widths were monitored throughout the experimental programme. The authors concluded that the presence of corrosioninduced cracks was the main cause of bond deterioration, and its impact was more substantial than changes in rebar shape or presence of rust at the interface, when in isolation. The fib Model Code 2010 [23] gives a simplified correlation between level of corrosion, crack width and bond degradation, with and without confining stirrups, and this is summarised in Table 1.

Table 1. Residual bond strength for corroded deformed bars, after fib Model Code 2010 [23]

\begin{tabular}{cccc}
\hline Confin. & $\begin{array}{c}\text { Corrosion } \\
\text { Penetration } \\
{[\mathrm{mm}]}\end{array}$ & $\begin{array}{c}\text { Equivalent } \\
\text { Surface Crack } \\
{[\mathrm{mm}]}\end{array}$ & $\begin{array}{c}\text { Residual } \\
\text { Capacity } \\
\text { (ratio to } f_{\text {bd }} \text { ) } \\
{[\%]}\end{array}$ \\
\hline No & 0.05 & $0.2-0.4$ & $50-70$ \\
Links & 0.10 & $0.4-0.8$ & $40-50$ \\
& 0.25 & $1.0-2.0$ & $25-40$ \\
\hline \multirow{2}{*}{ Links } & 0.05 & $0.2-0.4$ & $95-100$ \\
& 0.10 & $0.4-0.8$ & $70-80$ \\
& 0.25 & $1.0-2.0$ & $60-75$ \\
\hline
\end{tabular}

Some of the published experimental results are compared in Figure 3, together with the simplified relationship from the Model Code. The results are divided in two separate plots. The first one (Figure 3.a) refers to specimens without any transverse reinforcement. The second plot (Figure 3.b) shows the results in the presence of shear links.

\section{Confined Specimens}

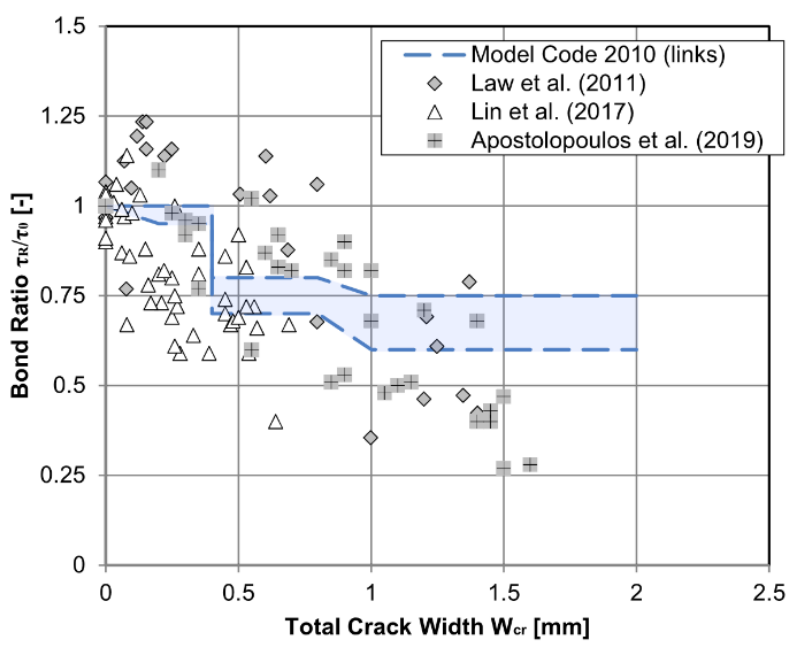

b)

Figure 3. Correlation between bond strength ratio and surface crack width, comparison of experimental results: a) Unconfined specimens; b) Specimens with transverse reinforcement. 
In the case of plain concrete, the plot shows a reasonably good correlation between surface crack widths and bond degradation. The Model Code predictions are conservative for unconfined specimens, which is to be expected in the case of guidance for practitioners. In the case of confined specimens, greater scatter in the results can be observed. Moreover, the Model Code provisions appear to overestimate the uplift due to confining reinforcement, resulting in unconservative predictions in some cases.

\section{Discussion}

The advantage of a crack-based approach is twofold. Firstly, the experimental evidence suggests that this approach can lead to more accurate results. It has been suggested that the main reason for this is that corrosion-induced surface cracks represent the net amount of corrosion that causes expansion and a loss of rib interlock. Secondly, the practical advantage consists in having a direct damage indicator that is visible and can be measured on the outer concrete surface. The rapid development of automated surveying technologies, such as inspection drones, allows for the acquisition of large quantities of high-quality visual data on infrastructure. Nonetheless, without an underpinning fundamental theory, a high-quality image of a crack is still just an image. A unified crack-based theory for the assessment of deteriorated structures has the potential to be the keystone for a new databased asset management framework using automated surveying and defect detection techniques. This would enable engineers to make more accurate predictions and automate the workflow, reducing the safety risks and maintenance costs of infrastructure management. Although promising, the available literature is limited and more research is necessary before reliable predictive models can be adopted. The influence of material properties should be further investigated. Geometrical parameters such as the cover, cover-to-diameter ratio, morphology of concrete cracks should also be investigated. The effect of confinement requires further research, as the experimental results show greater scatter in the presence of transverse reinforcement.

\section{Conclusions}

A new approach to the assessment of corrosioninduced bond deterioration of deformed steel bars in concrete has been investigated in recent years. This approach adopts a different perspective on the deterioration mechanisms responsible for the reduction in bond strength whereby bond reduction is related directly to crack width. From a critical analysis of the available results, the following conclusions can be drawn:

- Concrete crack widths can be a better indicator then corrosion levels to evaluate bond strength degradation;

- More research is necessary to develop accurate and reliable models of bond deterioration of general applicability. The influence of relevant parameters should be further investigated. These include material quality, type of corrosion products, cover, bar size, cover/diameter ratio, characteristics of cracks and cracking pattern, confinement.

\section{Acknowledgements}

The first author gratefully acknowledges the financial support of the United Kingdom Engineering and Physical Science Research Council (EPSRC) via a Doctoral Training Award [EP/M508007/1; EP/N509620/1].

\section{References}

[1] Jamali A., Angst U., Adey B., Elsener B. Modeling of corrosion-induced concrete cover cracking: A critical analysis. Construction and Building Materials. 2013; 42:225-237.

[2] Bossio A., Lignola G., Fabbrocino F., Monetta T., Prota A., Bellucci F., Manfredi G. Nondestructive assessment of corrosion of reinforcing bars through surface concrete cracks. Structural Concrete. 2017; 18(1):104-117.

[3] Mak M.W.T., Desnerck P., and Lees J.M. Corrosion-induced cracking and bond strength in reinforced concrete. Construction and Building Materials. 2019; 208: 228-241.

[4] Zhao Y., Yu J., Hu B., Jin W. Crack shape and rust distribution in corrosion-induced cracking concrete. Corrosion Science. 2012; 55:385-93. 
[5] fib, Bulletin 10 - Bond of Reinforcement in Concrete. 2000; Fédération Internationale du Béton (fib).

[6] Mancini G., Tondolo F. Effect of bond degradation due to corrosion $A$ literature survey. Structural Concrete. 2014; 15(3):408-418.

[7] Lin H., Zhao Y., Feng P., Ye H., Ozbolt J., Jiang C., Yang J.Q. State-of-the-art review on the bond properties of corroded reinforcing steel bar. Construction and Building Materials. 2019; 213:216-33.

[8] Tang D., Molyneaux T.K., Law D.W., Gravina R. Influence of Surface Crack Width on Bond Strength of Reinforced Concrete. $\mathrm{ACl}$ Materials Journal. 2011; 108(1): 29-37.

[9] Fischer C. and Ožbolt J. An appropriate indicator for bond strength degradation due to reinforcement corrosion. In Proceedings of the 8th International Conference on Fracture Mechanics of Concrete and Concrete Structures (FraMCoS-8), 14 March 2013, Toledo, Spain. 2013; 1828-1835.

[10] Coccia S, Imperatore S, Rinaldi Z. Influence of corrosion on the bond strength of steel rebars in concrete. Materials and structures. 2016; 49:537-551

[11] Al-Sulaimani G.J., Kaleemullah M., Basunbul I.A. Influence of corrosion and cracking on bond behavior and strength of reinforced concrete members. ACl Structural Journal. 1990; 87(2):220-231.

[12] Almusallam A.A., Al-Gahtani A.S., Aziz A.R. Effect of reinforcement corrosion on bond strength. Construction and Building materials. 1996; 10(2):123-129.

[13] Cabrera J.G. and Ghodoussi P. The effect of reinforcement corrosion on the strength of the steel/concrete bond. In Proceedings of the International Conference on Bond in Concrete: from Research to Practice. 15-17 October 1992, Riga, Latvia.1992; 10-12

[14] Fang C, Lundgren K, Chen L, Zhu C. Corrosion influence on bond in reinforced concrete. Cement and Concrete Research. 2004; 34(11):2159-67.
[15] Fischer C., Ožbolt J., Gehlen C. Numerical investigation on bond behavior of corroded reinforcement. In Proceedings of the 7th International Conference on Fracture Mechanics of Concrete and Concrete Structures (FraMCoS-7), 22-27 May 2010, Jeju, South Korea. 2010; 779-785.

[16] Law D.W., Tang D., Molyneaux T.K., Gravina R. Impact of crack width on bond: confined and unconfined rebar. Materials and Structures. 2011; 44(7): 1287-1296.

[17] Lin H., Zhao Y., Ožbolt J., Reinhardt H.W. Bond strength evaluation of corroded steel bars via the surface crack width induced by reinforcement corrosion. Engineering Structures. 2017; 152:506-522

[18] Banba S., Abe T., Nagaoka K., Murakami Y. Evaluation method for bond-splitting behavior of reinforced concrete with corrosion based on confinement stress of concrete against corrosion expansion. Journal of Advanced Concrete Technology. 2014; 12(1):7-23.

[19] Tepfers R. Cracking of concrete cover along anchored deformed reinforcing bars. Magazine of concrete research. 1979; 31(106):3-12.

[20] Apostolopoulos C.A., Koulouris K.F., Apostolopoulos A.C. Correlation of Surface Cracks of concrete due to corrosion and bond strength (between steel bar and concrete). Advances in Civil Engineering. 2019; 1-12.

[21] Tahershamsi M., Fernandez I., Lundgren K., Zandi K. Investigating correlations between crack width, corrosion level and anchorage capacity. Structure and Infrastructure Engineering. 2017; 13(10):1294-1307.

[22] Yang Y., Nakamura H., Miura T., Yamamoto Y. Effect of corrosion-induced crack and corroded rebar shape on bond behavior. Structural Concrete. 2019; 20(6):2171-2182.

[23] fib, Model Code 2010. 2010; Fédération Internationale du Béton (fib).

[24] Mangat, P.S. and Elgarf, M.S. Bond characteristics of corroding reinforcement in concrete beams. Materials and Structures. 1999; 32(2): 89. 